\title{
Prostaatspecifiek membraanantigeengestuurde chirurgie voor prostaatkanker
}

\author{
Pim J. van Leeuwen · Matthias N. van Oosterom · Hilda de Barros · Maarten L. Donswijk · Henk G. van der Poel • \\ Fijs W. B. van Leeuwen
}

Published online: 26 August 2020

(c) The Author(s) 2020

Samenvatting Real-time intraoperatieve begeleiding tijdens prostaatkankerchirurgie kan helpen bij de realisatie van een volledige en veilige resectie van de primaire tumor en/of de lymfekliermetastasen. Radio- en fluorescentiegeleide chirurgie zijn veelbelovend voor chirurgen die complexe chirurgische interventies uitvoeren. Dit soort begeleiding kan gerealiseerd worden met behulp van receptorgebonden tracers. De introductie van positronemissietomografie (PET) radiofarmaca die zijn gericht op het prostaatspecifieke membraanantigeen (PSMA) heeft geleid tot verbeterde stadiëring, vooral bij mannen met een recidief prostaatkanker en relatief lage PSA-waarden. Deze PSMA-receptor kan ook als target dienen voor het betrouwbaar peroperatief identificeren van kleine en/of atypisch gelokaliseerde laesies en/of tumorresiduen na primaire resectie. In dit overzicht bespreken we de huidige inzichten van op PSMA gebaseerde radio- en fluorescentiegeleide chirurgie.

dr. P. J. van Leeuwen $(\bowtie) \cdot$ dr. M. N. van Oosterom • drs. H. de Barros · dr. H. G. van der Poel . prof. dr. F. W. B. van Leeuwen

afdeling Urologie, Nederlands Kanker Instituut - Antoni van Leeuwenhoek, Amsterdam, Nederland

pj.v.leeuwen@nki.nl

dr. P. J. van Leeuwen · dr. H. G. van der Poel

Prostaatkankernetwerk Nederland, Amsterdam, Nederland

dr. M. N. van Oosterom • prof. dr. F. W. B. van Leeuwen Interventional Molecular Imaging Laboratory, afdeling Radiologie, Leids Universitair Medisch Centrum, Leiden, Nederland

drs. M. L. Donswijk

afdeling Nucleaire Geneeskunde, Nederlands Kanker

Instituut - Antoni van Leeuwenhoek, Amsterdam,

Nederland
Trefwoorden prostaatcarcinoom - PSMA · PET . radiogeleide chirurgie $\cdot$ fluorescentiechirurgie

\section{Prostate specific membrane antigen as target for surgical guidance}

Abstract Real-time intraoperative guidance is likely to support complete and safe resection of primary tumor and lymph node metastases in prostate cancer patients. Radio- and fluorescence-guided surgery has both shown potential for guiding surgeons during complex interventions. In this setting the targeting of disease specific receptors (biomarkers) can help to define the oncological target. The introduction of positron emission tomography radiopharmaceuticals that target the prostate specific membrane antigen (PSMA) has led to substantial staging improvements, especially in men with recurrent prostate cancer with low PSA values. The same PSMA receptor has the potential to provide reliable intraoperative identification of small and/or atypically localized lesions and/or residual disease. In this overview, we discuss the first clinical evidence and latest developments in the field of PSMA based radio- and fluorescence-guided surgery.

Keywords prostate cancer · PSMA - PET . radioguided surgery $\cdot$ fluorescence guided surgery

\section{Introductie}

Prostaatkanker is de meest voorkomende vorm van kanker bij mannen; in 2019 werd deze diagnose gesteld bij 13.600 mannen in Nederland. Ondanks verbeteringen in diagnostische en behandelingsmodaliteiten blijft prostaatkanker een van de meest frequente doodsoorzaken door kanker in Nederland. 
In een curatieve opzet is de radicale prostatectomie, met of zonder een pelviene lymfeklierdissectie, wereldwijd een van de meest gekozen behandelingen voor mannen met gelokaliseerde prostaatkanker [1] Deze ingreep is succesvol wanneer naast een goede oncologische uitkomst (volledige tumorresectie) ook de seksuele functie en continentie behouden blijven, de zogeheten drie-eenheid [2]. Bij radicale prostatectomie kan het percentage onveilige tumorresecties of positieve chirurgische marges op tot $38 \%[3,4]$. De percentages waarbij na (salvage) pelviene lymfeklierdissectie met postoperatieve PET-beeldvorming nog pelviene lymfekliermetastasen zichtbaar zijn, kan oplopen tot $63 \%$. Dit is suggestief voor incomplete resectie [5]. Gevoelige tumorspecifiekere beeldvormende technieken waarmee intraoperatief laesies kunnen worden geïdentificeerd, zouden een oplossing zijn voor het verwijderen van alle laesies die ook zichtbaar waren op de preoperatieve beeldvorming.

De introductie van de nieuwe radiofarmaca voor PET, die zijn gericht op het prostaatspecifieke membraanantigeen (PSMA), heeft de laatste jaren voor een revolutie gezorgd bij de detectie van prostaatkanker [6-8]. De hierbij gebruikte en intraveneus toegediende radiotracers binden zich aan de massaal aanwezige PSMA-recepteren (een transmembraaneiwit) op het oppervlak van prostaatkankercellen [9]. Deze overexpressie vindt plaats in zowel de primaire tumoren als in metastatische laesies (lymfeklieren en bot). Door de hoge specificiteit en redelijk goede sensitiviteit van PSMA PET is het mogelijk gebleken metastatische laesies te visualiseren bij lage prostaatspecifieke antigeen (PSA) waarden [10]. Bewijs van niveau $2 \mathrm{~b}$ (bewijs van ten minste één goed uitgevoerde quasi-experimentele studie), dat is gebaseerd op superieure detectiepercentages van terugkerende prostaatkanker na radicale prostatectomie bij lage PSA-waarden, heeft geleid tot een zwakke aanbeveling voor het uitvoeren van PSMA PET door de European Association of Urology bij mannen met PSA $>0,2 \mathrm{ng} / \mathrm{ml}$ na radicale prostatectomie.

Het is gebleken dat de basis van de PSMA-specifieke PET-radiofarmaca ook goed gebruikt kan worden om andere diagnostische labels te introduceren voor bijvoorbeeld single photon emmission computed tomography (SPECT) of fluorescentiebeeldvorming. Dit maakt het mogelijk om het preoperatieve gebruik van PSMA PET intraoperatief te complementeren met op PSMA gerichte radio- en/of fluorescentiegeleiding. Doel van dit overzichtsartikel is het bespreken van de theorie en de eerste klinische resultaten van op PSMA gerichte radio- en fluorescentiegeleide chirurgie voor de behandeling van prostaatkanker.

\section{Beeldvorming PSMA PET}

PSMA is weliswaar niet zo specifiek als de naam doet vermoeden, maar vertoont een significante overexpressie (100- tot 1.000-voudig) op de meeste prostaatkankercellen (>90\%) [9]. In de afgelopen 10 jaar zijn verschillende kleine radiofarmaca ontwikkeld voor de stadiëring en herstadiëring van prostaatkanker middels PET [11]. Hierbij wordt er optimaal gebruikgemaakt van de hoge gevoeligheid en spatiële resolutie van PET [8]. Vanzelfsprekend is de detectiegevoeligheid direct gekoppeld aan het niveau van PSMA-overexpressie in een metastase [10]. Deze effectiviteit in combinatie met de spatiële resolutie $(2 \mathrm{~mm}$ in moderne PET-systemen) betekent dat de kans op detectie afneemt met de omvang van de laesie. In een analyse bij patiënten met recidiefprostaatkanker die een salvage lymfeklierdissectie hadden ondergaan, was de detectiekans van PSMA PET voor metastasen meer dan $50 \%$ en $90 \%$ wanneer de diameter van de metastatische laesie op de korte as respectievelijk groter was dan 2,3 en $4,5 \mathrm{~mm}$ [12]. Bij primaire lymfekliermetastasen werd middels een preoperatieve PSMA PET $0 \%$ van de lymfekliermetastasen $<2 \mathrm{~mm}$ gedetecteerd, $60 \%$ van de lymfekliermetastasen met een doorsnee van $2-4,9 \mathrm{~mm}$ en $86 \%$ van de lymfekliermetastasen $\geq$ $5 \mathrm{~mm}$ [13]. De dracht van de positronen in weefsel beperkt de intrinsieke ruimtelijke resolutie van klinische PET-beeldvorming en is afhankelijk van de gebruikte radionuclide (bijv. ${ }^{68} \mathrm{Ga}$ of ${ }^{18} \mathrm{~F}$ ). Als gevolg hiervan kunnen micrometastasen $(<2 \mathrm{~mm})$ niet nauwkeurig door PSMA PET gedetecteerd worden. Desalniettemin presteert PSMA PET beduidend beter dan ${ }^{18} \mathrm{~F}$-Choline PET en conventionele CT of MRI. Deze technieken kunnen namelijk alleen metastasen detecteren als deze groter zijn dan 8-10 mm [6, 14, 15].

\section{Op PSMA gebaseerde radiogeleide chirurgie}

De intraoperatieve, op PSMA gebaseerde radiogeleide chirurgie is in 2014 voor het eerst toegepast bij prostaatkankerpatiënten in München. Bij deze radiogeleide chirurgie werd preoperatief intraveneus een radioactief gelabelde PSMA-ligand toegediend om de intraoperatieve detectie van kleine en atypisch gelokaliseerde metastatische prostaatkankerlaesies te vergemakkelijken met behulp van een gammaprobe. In eerste instantie werd PSMA-radiogeleide chirurgie uitgevoerd met een ${ }^{111}$ Indium $\left({ }^{111} \mathrm{In}\right)$ gelabelde PSMA-ligand. Vervolgens werd een ${ }^{99 \mathrm{~m}} \mathrm{Technetium}$ $\left({ }^{99 \mathrm{~m} T c}\right)$ gelabelde PSMA-ligand ontwikkeld ${ }^{99 \mathrm{~m}} \mathrm{Tc}-$ PSMA-I\&S) [16]. ${ }^{99 \mathrm{~m} T c}$ is een veelgebruikt radionuclide in de nucleaire geneeskunde, met gunstige stralingseigenschappen en beschikbaarheid. Het heeft een halveringstijd van zes uur en levert een relatief lage stralingsbelasting op voor patiënten en medisch personeel [17]. Na selectie voor radiogeleide chirurgie (gebaseerd op PSMA PET), ontvangt de patiënt circa 20 uur voor de operatie een intraveneuze injectie van het ${ }^{99 \mathrm{~m}} \mathrm{Tc}-\mathrm{PSMA}-\mathrm{I} \& \mathrm{~S}$. Vervolgens wordt met preoperatieve scintigrafie, inclusief SPECT/CT, de fysiologische biodistributie van de radiotracer en de verhoogde traceropname van het recidief prostaatkanker bevestigd. Bij gebruik van ${ }^{99 m}$ Tc-PSMA-I\&S voor open chirurgie kunnen verdachte laesies intraoperatief ge- 

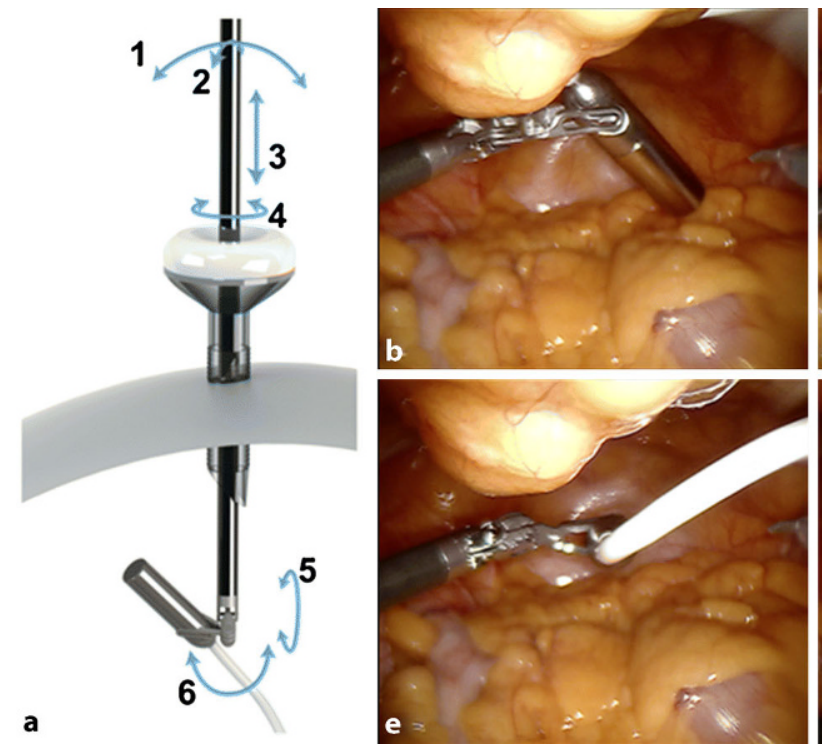

Figuur 1 De figuur toont de bewegingsvrijheid van de DROP-IN probe. a De da Vinci ${ }^{\circledR}$ ProGrasp ${ }^{\circledR}$ forceps werd geïntroduceerd via de trocar geplaatst in de linker onderbuik. De

lokaliseerd en geïdentificeerd worden met behulp van een standaard gammaprobe (met akoestische en numerieke feedback), die in de meeste ziekenhuizen al beschikbaar is voor schildwachtklierprocedures. Om succesvolle resectie direct te valideren, kunnen de weggehaalde weefselmonsters ex vivo opnieuw gemeten worden (positief of negatief in vergelijking met de achtergrond). Maurer et al. lieten in een retrospectieve analyse zien dat er een directe relatie was tussen de radioactieve inhoud (positief versus negatief) van tijdens ${ }^{99 m}$ Tc-PSMA-I\&S-RGS verwijderd weefsel en de postoperatieve histopathologische analyse daarvan [18]. Deze bevindingen resulteerden in een specificiteit van meer dan $95 \%$ voor ${ }^{99 m}$ Tc-PSMA$\mathrm{I} \& \mathrm{~S}$.

Binnen prostaatkankermanagement is het toepassen van minimaal-invasieve ingrepen in toenemende mate de standaard geworden. Dit heeft alleen wel direct impact op het gebruik van gammaprobes. Rigide laparoscopische gammasondes kunnen wel gebruikt worden in de laparoscopische setting. Deze sondes zijn in vivo echter beperkt manoeuvreerbaar, wat de intraoperatieve detectie limiteert. Deze beperking geldt voornamelijk voor laesies op moeilijk bereikbare locaties en laesies met lage activiteit die zich in de buurt bevinden van gebieden met een hoge achtergrond, zoals de nieren.

Om dit probleem op te lossen, hebben van Oosterom et al. een drop-in gammasonde ontwikkeld die, vooral met robotische instrumenten, een sterk toegenomen bewegingsvrijheid oplevert. Afhankelijk van hoe de drop-in wordt opgepakt, levert deze bewegingsvrijheid een effectief scanbereik van 0 tot $180^{\circ}$ rondom de tip van het chirurgische instrument. De eerste klinische studies onderstrepen dat de drop-in gammasonde een waardevol hulpmiddel is voor ro-
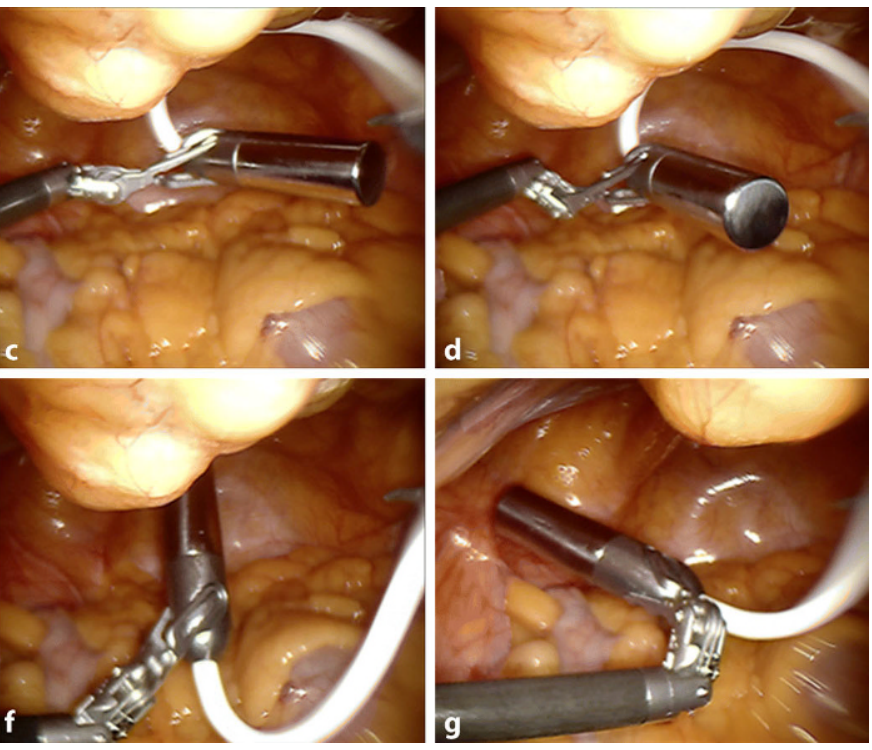

kleine gamma probe past op de forceps en kan door de chirurg in de verschillende richtingen worden gemanoeuvreerd $(\mathbf{b}-\mathbf{g})$

botgeassisteerde radiogeleide chirurgie, inclusief op PSMA gerichte resectie (fig. 1; [19-21]).

Bij $66 \%$ van de grootste onderzochte groep ( $n=121)$ waarin bij $99 \%$ van de patiënten metastatische laesies werden verwijderd (salvage lymfeklierdissectie) leidde een PSMA-radiogeleide operatie tot een volledige biochemische respons [22]. De mediane biochemischvrije overleving was 6,4 maanden voor de gehele groep en 19,8 maanden voor patiënten met een complete biochemische respons. Lage PSA-waarden en een individuele laesie op de PSMA PET-scan werden geassocieerd met een grotere kans op volledige biochemische respons (84\%) en een significant langere biochemischvrije overleving [23]. Deze oncologische resultaten zijn significant beter dan die in een vergelijkbaar grote serie van op PSMA PET gebaseerde conventionele salvage pelviene lymfeklierdissectie waarbij de biochemische respons $48 \%$ was en de mediane biochemischvrije overleving 3,3 maanden [24]. Het verdient alleen wel aanbeveling om te vermelden dat er tot op heden geen gerandomiseerde onderzoeken zijn uitgevoerd die op PSMA-gebaseerde radiogeleide chirurgie vergeleken hebben met een conventionele chirurgische benadering, waarbij het dissectieveld uitsluitend gebaseerd is op preoperatieve beeldvorming met PSMA PET.

In zijn algemeenheid vertegenwoordigt PSMAradiogeleide chirurgie waarbij een combinatie van preoperatieve en intraoperatieve beeldvorming wordt toegepast, een individueel behandelconcept dat op dit moment nog niet is opgenomen in de richtlijn. Het is niet bewezen dat de benadering een positief effect heeft op kwaliteit van leven of de kankerspecifieke overleving, ondanks de grote hoeveelheden proofof-principlegegevens. Grotere patiëntenaantallen en langdurige vervolgstudies zullen nodig zijn om het 
klinische voordeel van PSMA-radiogeleide chirurgie te bepalen. Deze studies moeten een vergelijking bevatten van behandelingsgerelateerde complicaties, de progressievrije overleving, de algehele overleving en de levenskwaliteit van prostaatkankerpatiënten. PSMA-radiogeleide chirurgie is niettemin haalbaar in open en (robotgeassisteerde) laparoscopische procedures en biedt daarmee de chirurg een hulpmiddel om de gerichtheid van de resecties te verfijnen. Dit kan uiteindelijk leiden tot verbeterde oncologische resultaten.

\section{Op PSMA gebaseerde fluorescentie geleide chirurgie}

Op het gebied van beeldgeleide chirurgie voor prostaatkanker is er naast radiogeleide chirurgie een toenemende belangstelling voor fluorescentiegeleide chirurgie. Fluorescentiebeeldvorming maakt gebruik van een gespecialiseerde lichtbron en camera om een fluorescerend farmacon mee te detecteren [25]. Het grote verschil met radiogeleide chirurgie is de beperkte weefselpenetratie van fluorescente signalen en het feit dat fluorescentie in real time visueel weergegeven kan worden. Hierdoor zou op PSMA gerichte fluorescentiegeleide chirurgie mogelijk een bijdrage kunnen leveren aan een van de voornaamste uitdagingen bij het chirurgisch behandelen van prostaatkanker: het bereiken van negatieve chirurgische resectiemarges [26]. Daarentegen zullen dieper gelegen tumorpositieve laesies (specifiek lymfeklieren) niet zichtbaar als deze bedekt worden door normaal weefsel (ook al bij een laag van $<1 \mathrm{~cm}$ ). De opname van de fluorescente PSMA-tracers en de opname van de PETen SPECT-tracers berusten op hetzelfde concept. Recentelijk zijn enkele PSMA-tracers voor gebruik in fluorescentiegeleide chirurgie preklinische gevalideerd $[27,28]$. Er moet echter worden opgemerkt dat de invivoresultaten van deze verschillende studies niet direct met elkaar kunnen worden vergeleken, aangezien de expressieniveaus van PSMA verschillen tussen de verschillende gebruikte tumormodellen en kwantitatieve informatie over de distributie van het farmacon meestal ontbreekt. Het is alleen wel duidelijk dat de hoeveelheid farmacon die nodig is voor fluorescentiegeleide chirurgie veel hoger ligt dan die voor radiogeleide chirurgie en dat fluorescente labels vaak de renale klaring van het farmacon verhogen. Er loopt een veelbelovende klinische studie aan de universiteit van Oxford in het Verenigd Koninkrijk met een op PSMA gebaseerd fluorofoor geconjugeerd middel (IR800 IAB2M). Voorlopige gegevens uit deze studie suggereren dat de fluorescentiebenadering haalbaar is tijdens robotgeassisteerde chirurgie. Wat de margebeoordeling betreft, blijkt de uitscheiding via de urine (resulterend in een storend achtergrondsignaal bij urinelekkage uit de blaas) een grote uitdaging. Dit effect is voor een groot deel gerelateerd aan de hoge dosis farmacon die gebruikt is en dus wordt er momenteel een dosisoptimalisatie uitgevoerd. Een nadeel van deze techniek is wel dat de distributie van de fluorescente farmaca niet non-invasief bepaald kan worden, en dus gedaan moet worden aan de hand van intraoperatieve beelden. Voor klinische scenario's is het noodzakelijk om tracers te ontwikkelen zonder renale klaring die bovendien effectief zijn bij een lage dosering. Ook is het wenselijk dat, net als bij radiogeleide chirurgie, preoperatief de accumulatie van het farmacon in de laesies gevalideerd kan worden. Ondanks de nadelen lijkt PSMA-fluorescentiegeleide chirurgie op dit moment een veelbelovend hulpmiddel voor de chirurg voor het bereiken van de volledige resectie van prostaatkanker. Er zijn echter goede klinische studies nodig, waarin bij voorkeur het effect van PSMA-fluorescentiegeleide chirurgie wordt vergeleken met het effect van de hiervoor beschreven radiogeleide chirurgie.

\section{PSMA Cerenkov-luminiscentie}

Weer een andere techniek om peroperatief de chirurgische snijranden tijdens radicale prostatectomie te beoordelen, is Cerenkov luminescence imaging [29, 30]. Cerenkov-luminescentie is een zwak licht dat wordt uitgezonden door een radioactieve verbinding [31]. Het zogenaamde Cerenkov-licht ontstaat op het moment dat een elektrisch geladen deeltje zich door een diëlektrisch medium verplaatst met een snelheid groter dan de fasesnelheid van licht in dat medium [32]. Op het moment dat het gepolariseerde medium terugkeert naar zijn grondtoestand, wordt breedspectrum elektromagnetische straling, bekend als Cerenkov-straling, uitgezonden. Naast een hoge sensitiviteit en specificiteit van PSMA voor de detectie van prostaatkankerlaesies middels PET, blijkt gallium$68{ }^{\left({ }^{68} \mathrm{Ga}\right)-P S M A}$ uitermate geschikt te zijn voor Cerenkov-luminescentie door de relatief hoge Cerenkovopbrengt. ${ }^{68} \mathrm{Ga}-\mathrm{PSMA}$ Cerenkov luminescence imaging is een beeldvormende techniek die het Cerenkovlicht, dat wordt uitgezonden door ${ }^{68} \mathrm{Ga}$-PSMA, detecteert met een zeer gevoelige camera (Lightpoint Medical Ltd) [31]. Deze techniek zou geschikt zijn voor patiënten met een PSMA-avide primaire tumor die in aanmerking komen voor radicale prostatectomie. Om van Cerenkov-luminescentie gebruik te kunnen maken, wordt er voor de start van de operatie een intraveneuze injectie met ${ }^{68} \mathrm{Ga}$-PSMA toegediend en wordt, direct na het verwijderen van de prostaat, het preparaat ex vivo onderzocht onder de speciale camera. Doordat de prostaat nog tijdens de operatie wordt afgebeeld, kunnen de snijranden van de verwijderde prostaat direct worden beoordeeld. Indien er met de speciale camera ${ }^{68} \mathrm{Ga}$-PSMA Cerenkovlicht wordt gedetecteerd, zou er in theorie sprake zijn van een positieve chirurgische resectiemarge (fig. 2). Naar deze werkwijze zijn inmiddels twee klinische haalbaarheidsstudies afgerond [33, 34]. Beide studies toonden aan dat ${ }^{68} \mathrm{Ga}$-PSMA Cerenkov luminescence 
Figuur 2 Voorbeeld van een afbeelding van de prostaat middels Cerenkov luminescence imaging. Links een doorsnede van het radicale prostatectomiepreparaat met ${ }^{68} \mathrm{Ga}-\mathrm{PSMA}-$ activiteit in de apex van de prostaat. Rechts een positieve chirurgische marge (PSM) aan de apex en aan de basis van de prostaat links (L), in dit voorbeeld bevestigd bij histopathologisch onderzoek
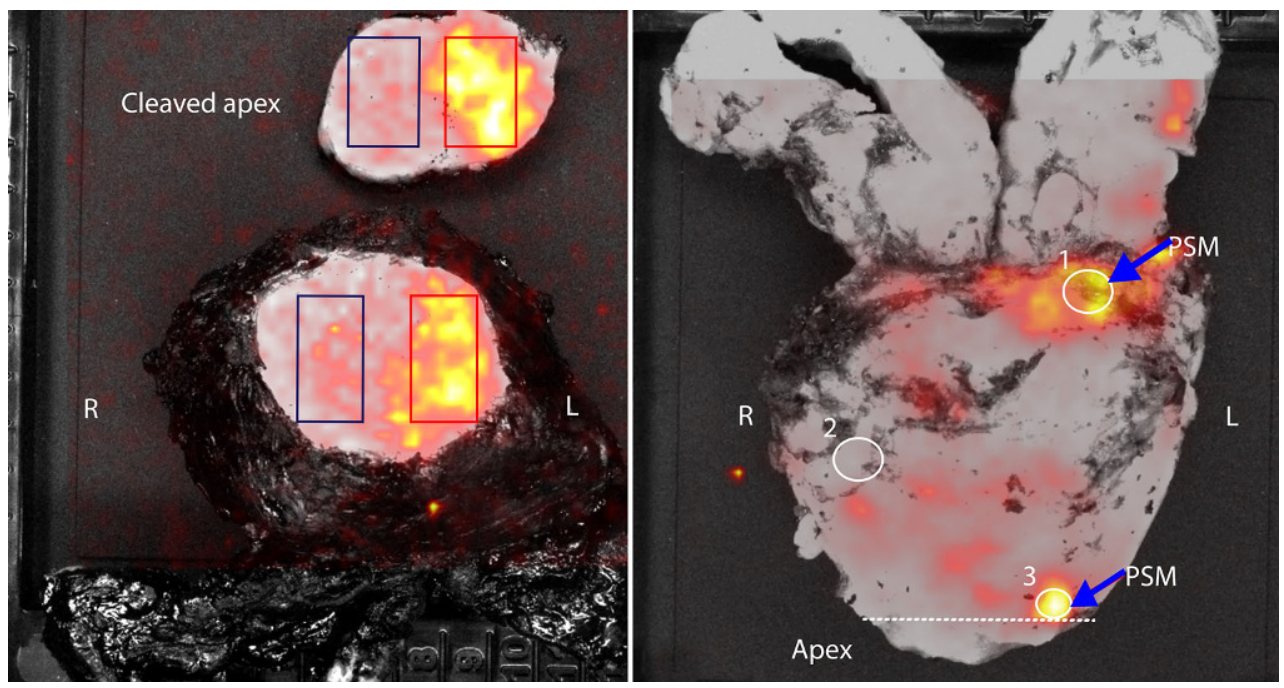

imaging een veelbelovende, veilige en goed uitvoerbare techniek is.

\section{Huidige studies naar op PSMA gebaseerde beeldgeleide chirurgie in Nederland}

Momenteel zijn er in Nederland vier prospectieve klinische studies geregistreerd die nader onderzoek doen naar op PSMA gebaseerde beeldgeleide chirurgie met als doel deze verder te ontwikkelen. Studies werden opgenomen in dit overzicht indien ze zijn geregistreerd op https://clinicaltrials.gov of https:// www.trialregister.nl en open zijn voor inclusie in een Nederlands ziekenhuis.

\section{${ }^{99 m}$ Tc based PSMA radioguided assisted surgery for prostate cancer (TRACE) feasibility study}

Doel Een prospectief haalbaarheidsonderzoek met ${ }^{99 m}$ Tc-PSMA-geleide chirurgie voor een robotgeassisteerde salvage pelviene lymfeklierdissectie met gebruik van DROP-IN-technologie voor mannen met een biochemisch recidief na radicale prostatectomie met op de PSMA PET-scan $\leq 3$ voor prostaatkanker verdachte laesies in het kleine bekken.

Inclusie 20 mannen met biochemisch recidief (PSA $<4,0 \mathrm{ng} / \mathrm{mL}$ ) na radicale prostatectomie met op de PSMA PET-scan $\leq 3$ voor prostaatkanker verdachte laesies in het kleine bekken.

Locatie Antoni van Leeuwenhoek/Nederlands Kanker Instituut.

\section{Radio guided lymph node dissection in} oligometastatic prostate cancer patients

Doel Een prospectief haalbaarheidsonderzoek met ${ }^{111}$ ln- PSMA-I\&T voor radiogestuurde robotgeassisteerde pelviene lymfeklierdissectie bij mannen met primair gediagnosticeerd prostaatkanker. Kandidaten hebben op de PSMA PET-scan een verdachte lymfeklier (N1) en worden behandeld middels een robotgeassisteerde radicale prostatectomie met pelviene lymfeklierdissectie.

Inclusie 20 mannen met primair gediagnosticeerd prostaatkanker met op de PSMA PET-scan verdachte lymfeklieren in het kleine bekken.

Locatie Canisius Wilhelmina Ziekenhuis.

Study for intraoperative imaging of prostate cancer using OTL78

Doel Een prospectieve fase II-studie naar de veiligheid, tolerantie en farmacokinetiek, sensitiviteit, specificiteit en toegevoegde intraoperatieve waarde voor de chirurg van OTL78, een op PSMA gebaseerd fluorescent farmacon, voor de intraoperatieve beeldvorming van prostaatkanker.

Inclusie deel B Zes patiënten met een biochemisch recidief na radicale prostatectomie bij wie een (salvage) pelviene lymfeklierdissectie gepland is.

Inclusie deel C 18 patiënten met primair gediagnosticeerd prostaatkanker bij wie een radicale prostatectomie gepland is.

Locatie Leids Universitair Medisch Centrum en Antoni van Leeuwenhoek/Nederlands Kanker Instituut.

\section{A feasibility study on Cerenkov luminescence imaging using Gallium-68 PSMA during prostate cancer surgery}

Doel De haalbaarheid van het Cerenkov luminescence imaging-apparaat om de resectieranden tijdens de operatie te beoordelen bij een radicale prostatec- 
tomie. De beelden van het Cerenkov luminescence imaging-apparaat worden vergeleken met de aanwezigheid, locatie en grootte van de histopathologie.

Inclusie 30 patiënten worden geïncludeerd bij wie een robotgeassisteerde radicale prostatectomie gepland is.

Locatie Antoni van Leeuwenhoek/Nederlands Kanker Instituut.

\section{De toekomst}

De laatste jaren zijn er met name preklinisch grote vorderingen gemaakt in beeldgeleide chirurgie voor prostaatkanker. In klinische studies zijn de meest veelbelovende resultaten geboekt met radiogeleide chirurgie bij patiënten met recidief prostaatkanker met beperkt aantal lymfekliermetastasen op PSMA PET. Met voortschrijdende technologieën, nieuwe tracers en fabricage van nieuwe chirurgische instrumenten is het waarschijnlijk dat deze vooruitgang in de toekomst een grotere impact zal krijgen op de klinische behandeling van prostaatkanker. Momenteel bestaat er een toenemende belangstelling voor op PSMA gebaseerde beeldgeleide chirurgie voor prostaatkanker in de primaire setting, in de context van margebepaling tijdens radicale prostatectomie. Als je de voor- en de nadelen van radiogeleide chirurgie en fluorescentiegeleide chirurgie naast elkaar zet, zijn vermoedelijk de dual-labelingsstrategieën (zogenaamde hybride farmaca) de meest veelbelovende ontwikkeling. Met deze benadering kan de chirurg gebruikmaken van de beste eigenschappen van de individuele chirurgische benaderingen[35]. Een hybride farmacon zou in potentie de beperking van radiogeleide chirurgie (geen real-time visualisatie) en fluorescentiegeleide chirurgie (geen preoperatieve 'road map' middels bijv. SPECT/CT, geen intraoperatieve sturing naar dieper gelegen afwijkingen) kunnen wegnemen. Helaas zijn deze hybride PSMA-farmaca tot nu toe alleen onderzocht in een preklinische setting, waarop varkens de grootste dieren zijn waarop is getest [28, 36-39]. De eerste klinische studies worden wel op korte termijn verwacht.

\section{Conclusie}

Op PSMA-gerichte radio- en fluorescentiegeleide chirurgie zijn veelbelovende technieken voor de chirurgische behandeling van prostaatkanker. De techniek is nog volop in ontwikkeling. Tot op heden zijn de meeste klinische resultaten geboekt met radiogeleide open chirurgie bij patiënten met een recidief prostaatkanker op de PSMA PET-scan. Recentelijk zijn ook in Nederland de eerste klinische studies gestart. Mede omdat het toepassen van minimaal-invasieve chirurgie in toenemende mate de standaard is geworden voor de behandeling van prostaatkanker, wordt er gewerkt aan verdere integratie van deze techniek in de (robotgeassisteerde) laparoscopische chirurgie. Deze integratie moet een bijdrage leveren aan een meer individuele chirurgische benadering van prostaatkanker, waarbij pre- en intraoperatieve beeldvorming worden gecombineerd, met als doel de oncologische uitkomsten en de levenskwaliteit van prostaatkankerpatiënten te verbeteren.

Open Access This article is distributed under the terms of the Creative Commons Attribution 4.0 International License (http://creativecommons.org/licenses/by/4.0/), which permits unrestricted use, distribution, and reproduction in any medium, provided you give appropriate credit to the original author(s) and the source, provide a link to the Creative Commons license, and indicate if changes were made.

\section{Literatuur}

1. Cary KC, Punnen S, Odisho AY, et al. Nationally representative trends and geographic variation in treatment of localized prostate cancer: the Urologic Diseases in America project. Prostate Cancer Prostatic Dis. 2015;18(2):149-54.

2. Bianco FJ Jr., Scardino PT, Eastham JA. Radical prostatectomy: long-term cancer control and recovery of sexual and urinary function ('trifecta'). Urology. 2005;66(5 Suppl):83-94.

3. Stephenson AJ, Wood DP, Kattan MW, et al. Location, extent and number of positive surgical margins do not improve accuracy of predicting prostate cancer recurrence after radical prostatectomy. J Urol. 2009;182(4):1357-63.

4. Izard JP, True LD, May P, et al. Prostate cancer that is within $0.1 \mathrm{~mm}$ of the surgical margin of a radical prostatectomy predicts greater likelihood of recurrence. Am J Surg Pathol. 2014;38(3):333-8.

5. Farolfi A, Ilhan H, Gafita A, et al. Mapping prostate cancer lesions pre/post unsuccessful salvage lymph node dissection using repeat PSMA-PET. J Nucl Med. 2020;61(7):1037-42.

6. Morigi JJ, Stricker PD, Leeuwen PJ van, et al. Prospective comparison of $18 \mathrm{~F}$-fluoromethylcholine versus $68 \mathrm{Ga}-$ PSMA PET/CT in prostate cancer patients who have rising PSA after curative treatment and are being considered for targeted therapy. J Nucl Med. 2015;56(8):1185-90.

7. Perera M, Papa N, Christidis D, et al. Sensitivity, specificity, and predictors of positive (68)Ga-prostate-specific membrane antigen positron emission tomography in advanced prostatecancer: a systematic reviewand meta-analysis. Eur Urol. 2016;70(6):926-37.

8. Luiting HB, Leeuwen PJ van, Remmers S, et al. The optimal timing for PSMA PET/CT in patients with biochemical recurrence after radical prostatectomy. J Urol. 2020 Sep;204(3):503-10.

9. Silver DA, Pellicer I, Fair WR, Heston WD, Cordon-Cardo C. Prostate-specific membrane antigen expression in normal and malignant human tissues. Clin Cancer Res. 1997;3(1):81-5.

10. Luiting HB, Leeuwen PJ van, Busstra MB, et al. Use of gallium-68 prostate-specific membrane antigen positronemission tomography for detectinglymph nodemetastases in primary and recurrent prostate cancer and location of recurrence after radical prostatectomy: an overview of the current literature. BJU Int. 2020;125(2):206-14.

11. Eiber M, Fendler WP, Rowe SP, et al. Prostate-specific membrane antigen ligands for imaging and therapy. J Nucl Med. 2017;58(Suppl2):67S-76S. 
12. Jilg CA, Drendel V, Rischke HC, et al. Diagnostic Accuracy of Ga-68-HBED-CC-PSMA-Ligand-PET/CT before salvage lymph node dissection for recurrent prostate cancer. Theranostics. 2017;7(6):1770-80.

13. Leeuwen PJ van, Emmett L, Ho B, et al. Prospective evaluation of 68 Gallium-prostate-specific membrane antigen positron emission tomography/computed tomography for preoperative lymph node staging in prostate cancer. BJU Int. 2017;119(2):209-15.

14. Visschere PJL de, Standaert C, Futterer JJ, et al. A systematic review on the role of imaging in early recurrent prostate cancer. Eur Urol Oncol. 2019;2(1):47-76.

15. Maurer T, Gschwend JE, Rauscher I, et al. Diagnostic efficacy of Gallium-PSMA-PET compared to conventional imaging in lymph node staging of of 130 consecutive patients with intermediate to high-risk prostate cancer. JUrol. 2016;195(5):1436-43.

16. Robu S, Schottelius M, Eiber M, et al. Preclinical evaluation and first patient application of99mTc-PSMA-I\&SforSPECT imaging and radioguided surgery in prostate cancer. J Nucl Med. 2017;58(2):235-42.

17. Povoski SP, Neff RL, Mojzisik CM, et al. A comprehensive overview of radioguided surgery using gamma detection probe technology. World J Surg Oncol. 2009;7:11.

18. Maurer T, Robu S, Schottelius M, et al. (99m)Technetiumbased prostate-specific membrane antigen-radioguided surgery in recurrent prostate cancer. Eur Urol. 2019;75(4):659-66.

19. Oosterom MN van, Simon H, Mengus L, et al. Revolutionizing (robot-assisted) laparoscopic gamma tracing using a drop-in gamma probe technology. Am J Nucl Med Mol Imaging. 2016;6(1):1-17.

20. Leeuwen FWB van, Oosterom MN van, Meershoek P, et al. Minimal-invasive robot-assisted image-guided resection of prostate-specific membrane antigen-positive lymph nodes in recurrent prostate cancer. Clin Nucl Med. 2019;44(7):580-1.

21. Meershoek P, Oosterom MN van, Simon H, et al. Robot-assisted laparoscopic surgery using DROP-IN radioguidance: first-in-human translation. Eur J Nucl Med Mol Imaging. 2019;46(1):49-53.

22. Horn T, Kronke M, Rauscher I, et al. Single lesion on prostate-specific membrane antigen-ligand positron emission tomography and low prostate-specific antigen are prognostic factors for a favorable biochemical response to prostatespecific membrane antigen-targeted radioguided surgery in recurrent prostate cancer. Eur Urol. 2019;76(4):517-23.

23. Afshar-Oromieh A, Vollnberg B, Alberts I, et al. Comparison of PSMA-ligand PET/CT and multiparametric MRI for the detection of recurrent prostate cancer in the pelvis. Eur J Nucl Med Mol Imaging. 2019;46(11):2289-97.

24. Siriwardana A, Thompson J, Leeuwen PJ van, et al. Initial multicentre experience of (68) gallium-PSMA PET/CT guided robot-assisted salvage lymphadenectomy: acceptable safety profile but oncological benefit appears limited. BJU Int. 2017;120(5):673-81.

25. Hernot S, Manen L van, Debie P, Mieog JSD, Vahrmeijer AL. Latest developments in molecular tracers for fluorescence image-guided cancer surgery. Lancet Oncol. 2019;20(7):e354-e67.

26. Bugby SL, Lees JE, Perkins AC. Hybrid intraoperative imaging techniques in radioguided surgery: present clinical applications and future outlook. Clin Transl Imaging. 2017;5(4):323-41.
27. Hensbergen AW, Willigen DM van, Welling MM, et al. Click chemistry in the design and production of hybrid tracers. ACS Omega. 2019;4(7):12438-48.

28. Oosterom MN van, Rietbergen DDD, Welling MM, Poel HG van der, Maurer T, Leeuwen FWB van. Recent advances in nuclear and hybrid detection modalities for image-guided surgery. Expert Rev Med Devices. 2019;16(8):711-34.

29. Das S, Thorek DL, Grimm J. Cerenkov imaging. Adv Cancer Res. 2014;124:213-34.

30. Grootendorst MR, Cariati M, Kothari A, Tuch DS, Purushotham A. Cerenkov luminescence imaging (CLI) for image-guided cancer surgery. Clin Transl Imaging. 2016;4(5):353-66.

31. DarrC, HarkeN, RadtkeJP, etal. Intraoperative (68)GalliumPSMACerenkovluminescenceImagingfor surgicalmargins in radical prostatectomy-a feasibility study. J Nucl Med. 2020. https://doi.org/10.2967/jnumed.119.240424.

32. Spinelli AE, D'Ambrosio D, Calderan L, Marengo M, Sbarbati A, Boschi F. Cerenkov radiation allows in vivo optical imaging of positron emitting radiotracers. Phys Med Biol. 2010;55(2):483-95.

33. Darr C, Krafft U, Fendler WP, et al. First-in-man intraoperative Cerenkov luminescence Imaging for oligometastatic prostate cancer using (68)Ga-PSMA-11. Eur J Nucl Med Mol Imaging. 2020. https://doi.org/10.1007/s00259-02004778-y.

34. Olde Heuvel J, Wit-van der Veen BJ de, Poel HG van der, et al. (68)Ga-PSMA Cerenkov Luminescence Imaging in primary prostate cancer: first-in-man series. Eur J Nucl Med Mol Imaging. 2020. https://doi.org/10.1007/s00259020-04783-1.

35. Leeuwen FWB van, Winter A, Poel HG van der, et al. Technologies for image-guided surgery for managing lymphatic metastases in prostate cancer. Nat Rev Urol. 2019;16(3):159-71.

36. Banerjee SR, Foss CA, Horhota A, et al. (111)In- and IRDye800CW-labeled PLA-PEG nanoparticle for imaging prostate-specific membrane antigen-expressing tissues. Biomacromolecules. 2017;18(1):201-9.

37. Baranski AC, Schafer M, Bauder-Wust U, et al. PSMA11-derived dual-labeled PSMA inhibitors for preoperative PET imaging and precise fluorescence-guided surgery of prostate cancer. J Nucl Med. 2018;59(4):639-45.

38. Schottelius M, Wurzer A, Wissmiller K, et al. Synthesis and preclinical characterization of the PSMA-targeted hybrid tracer PSMA-I\&F for nuclear and fluorescence imaging of prostate cancer. J Nucl Med. 2019;60(1):71-8.

39. Hensbergen AW, Buckle T, Willigen DM van, et al. Hybrid tracers based on cyanine backbones targeting prostatespecific membrane antigen: tuning pharmacokinetic properties and exploring dye-protein interaction. J Nucl Med. 2020;61(2):234-41.

dr. Pim J. van Leeuwen, uroloog

dr. Matthias N. van Oosterom, post-doc

drs. Hilda de Barros, promovendus

drs. Maarten L. Donswijk, nucleair geneeskundige

dr. Henk G. van der Poel, uroloog

prof. dr. Fijs W.B. van Leeuwen, hoogleraar Moleculaire beeldvorming en beeldgeleide therapie 